\title{
Teachers' Learning and Innovation Skills Development: Challenge and Changing Based on Professional Learning Community
}

\author{
Adul Paison ${ }^{1}$, Chowwalit Chookhampaeng ${ }^{1}, \&$ Aperadee Jansang ${ }^{2}$ \\ ${ }^{1}$ Department of Curriculum and Instruction, Faculty of Education, Mahasarakham University, Thailand \\ ${ }^{2}$ Department of Geography and History, Faculty of Humanities and Social science, Mahasarakham University, \\ Thailand \\ Correspondence: Adul Paison, Faculty of Education, Mahasarakham University, Thailand. Tel: 66-04-259-9626. \\ E-mail: adul245@gmail.com
}

Received: July 19, 2015 Accepted: September 30, 2015 Online Published: November 20, 2015

doi:10.5539/ass.v11n27p115 URL: http://dx.doi.org/10.5539/ass.v11n27p115

\begin{abstract}
This study was aims to investigate the effects of teacher development program based on Professional Learning Community (PLC) on teachers' learning and innovation skills. The sample group for implementing the program was 10 Thai language teachers in grade 3. The instruments consisted of the observation form, and the performance assessment form. Mean and standard deviation were used to describe the data. The results of this study found that the sample group was conduct the learning and innovation skills at highest level and the innovation of sample groups were the innovation to promote learning and innovation skills at highest level, mean 4.90 and standard deviation 0.02 .
\end{abstract}

Keywords: learning and innovation skills, professional learning community, teacher development

\section{Introduction}

In each year, teachers receive develops rather more, but the content unclear that useful, because the training mostly develops knowledge, lack developing the skills, thus they lack the skills on instruction; therefore they used media and innovation in teaching less. Thus affects the learner lack the important basic skills to learning and living in complex society (Office of the Educational Council, 2010a). Teacher development must develop to have ability and skills on the job and the development must non-impact on schoolings' time (Office of the Educational Council, 2010b).

The Learning and Innovation Skills are the set of skills that consisted creativity and innovation, critical thinking and problem solving, communication and collaboration, which are critical skills in $21^{\text {st }}$ century (Partnership for 21 st Century Skills, 2009). Because who have these skills, they will the expertise in thinking, uses reasoning and effective decision to solving complex problem, uses clearly communication both speaking and writing in communication elaborate stories and collaborated with the other creatively. Apply ideas and imagination to create innovation and uses it creatively, which are the attributes of people in $21^{\text {st }}$ century that society need very much, therefore professional development by training $21^{\text {st }}$ century skills for every teachers, to them change the assessment and instruction it is important (Panit, 2012).

The PLC creation based on PLC approach is a method to help teacher change the role from instructor as facilitator in learning, to help the learner learning by doing for living in $21^{\text {st }}$ century age, because PLC is a tool for the teachers incorporate be community, collaborate create innovation, the experience sharing, to the classroom action research on the powerful, research design, data collection, data analysis and synthesis the research results be a new knowledge, that link to social context and the real life of learner (Panit, 2012). The PLC is a methodology that principal, staff, and teacher, collaborative problem solving and develop the instruction for learner achieve the educational goals (Hord, 2010). Owing to, PLC approach believe that individual people can't do in everything, thus collaboration to problem solving and develop the learner, the teacher must develop knowledge and skills by collaborative learning, sharing knowledge in schooling problem solving, through conversation and listening the ideas of others intently (Dufour \& Dufour, 2012). Factor affecting the PLC is principal's support, monitoring, and encourage participation in decision of teacher (Vescio et al., 2008; Chou, 2011). The PLC participation of teacher in same class level, taught the same subject, 
collaborative learning will contribute to enhance the professional (Graham, 2007; Rentfro, 2007). Learning from the experts and collaborating with colleague to share best practice and After Action Review (AAR) regularly are important strategies for instruction and assessment (Chou, 2011; Williams et al., 2012).

This research describes and analyzes the professional development of a group of Thai in-service elementary teachers, involved in a professional learning community initiated by the researchers. It was first based on the methodological principles of Professional Learning Community (PLC) (Lieberman, 1995; Rentfro, 2007) and then it followed the educational trends of professional learning communities in which teachers collaboratively conducted research within their local community (Snow-Gerono, 2005; Vescio et al., 2008; Chou, 2011). The aim of this study is investigate the effects of teacher development program based on Professional Learning Community (PLC) on teachers' learning and innovation skills, and how a teachers' learning community can contribute to teachers' development.

\section{Method}

\subsection{Participants and Procedures}

The study described in this article is part of a teacher development program based on professional learning community. The samples selection used the strategy of purposive sampling to selected participants from ten schools in Nakhon Phanom primary Educational Service Area Office 2, Nakhon Phanom Province, Thailand. Ten Thai language teachers in grade 3(same grade level) who showed interest and voluntary join this program and approval was obtained from the school principal.

This study used the action research which research's cycle includes planning, acting, observing, and reflecting as shown in Figure 1. The action research is characterized as sequenced stage of research design (Kemmis \& Mc Taggart, 1988). The participants were received learning to created schoolings' innovation through three main activities involved workshop (twenty five hours), classroom action research (sixty hours) and symposiums (six hours). In activities, they had to collaborative learning, charring best practices, and reflecting observed result by using After Action Review (AAR). Ten indicators of behaviors includes the skills of reasoning abilities, analyzing and evaluating ways, decision making and judgment, problems solving, using creation techniques, work creatively with others, creative and implement innovations, oral communication, written communication, and collaborate with others, its ten indicators for used in ten items of the observation form and performance assessment form.

\subsection{Measures}

The concepts in this study were behaviors' observing and performance assessment participants' practice; instruments consisted of the observation form and performance assessment form. The measurements were used rating scale from 1 to 5 scales (Likert-type scale) and rubric score five levels (very low, low, medium, high and highest). The measurement had 10 items used assess in 3 sides consisted, critical thinking and problem solving skills (4 items), creativity and innovation skills (3 items) and communication and collaboration skills ( 3 items).

\subsection{Data Analysis}

Mean and Standard deviation were used to analyze data from observation and performance assessment of participants, data analysis by using the computer program and data presentation by using table and descriptive.

\section{Results}

The participants' behavior as presented as shown in Figure 2 and the participants' performance assessment presented as shown in Table 1. This study investigated Learning and Innovation Skills of teachers whom participants in 3 sides were as critical thinking and problem solving skills, creativity and innovation skills and communication and collaboration skills. The results of this study found that: the participants have Learning and Innovation Skills in highest level, such as critical thinking and problem solving skills, they have reasoning ability with accurate information to support, use evidences and examples for explanation at consistent, create the choice to work and describes the results clearly, judgmental based on analytical and assessing the evidence, use argument by cited the evidence, solve the problem systematically by defining the problem, collect data, analyze issues, plan and implemented solutions, assess the impact that occurs, create the standard on a solution, and can evaluate operational. The creativity and innovation skills, they can share ideas and findings, decision-making better, have curiosity, enthusiasm in the solution, a flexibility and openness to new experiences, adaptation well, likes complex working, have self-confidence, engagement with the work assigned. And the communication and collaboration skills, they able to speak clearly on its objectives have knowledge as well and match the audience, and know how to create an atmosphere of speech, can write with the correct language in a variety of formats for communication purposes, can adapt well to the group, appreciative of collaboration and shared responsibility for 
the outcome of the group. And they can design Innovation focused on enhancing Learning and Innovation Skills of learners, which appear in the activities of innovation that they use to solve students' reading.

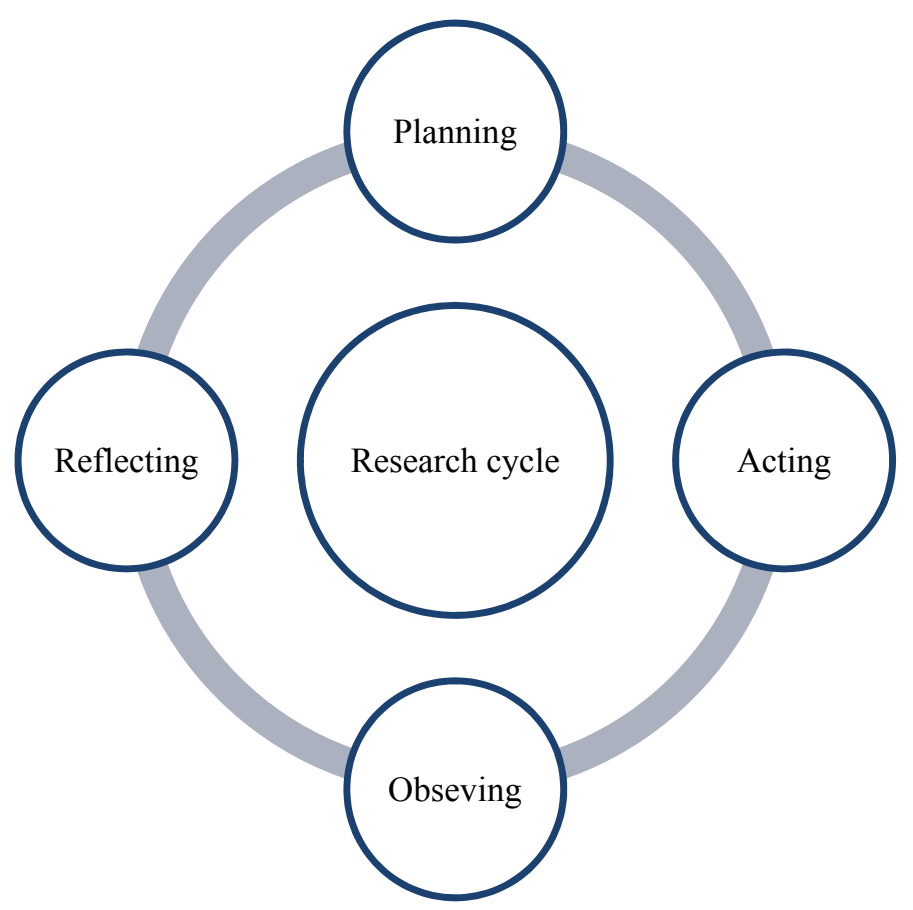

Figure1. Research cycle

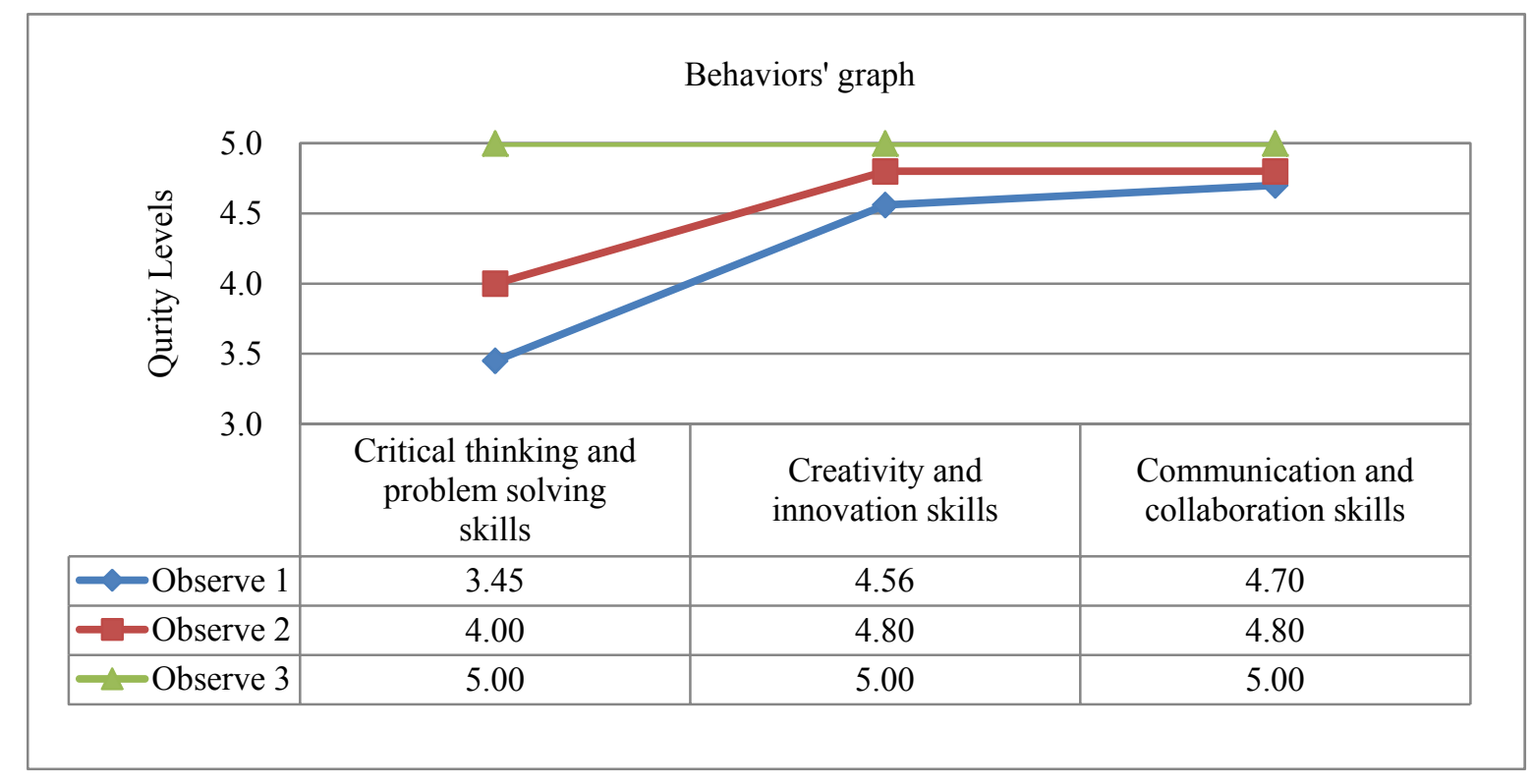

Figure 2. Behaviors' Graph

Note. $0.01-1.50=$ Very low level, $1.51-2.50=$ Low level, $2.51-3.50=$ Medium level, $3.51-4.50=$ High level, $4.51-5.00=$ Highest level 
Table 1. Mean and Standard deviation, schoolings' innovation assessment

\begin{tabular}{|c|c|c|c|c|c|c|}
\hline \multirow[b]{2}{*}{ 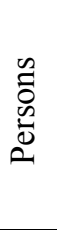 } & \multicolumn{3}{|c|}{ Assessment catalogue $(\mathrm{N}=10)$} & \multirow[b]{2}{*}{$\overline{\mathrm{X}}$} & \multirow[b]{2}{*}{ S.D. } & \multirow[b]{2}{*}{ Explanations } \\
\hline & $\begin{array}{c}\text { Critical thinking and } \\
\text { problem solving } \\
\text { skills }\end{array}$ & $\begin{array}{l}\text { Creativity and } \\
\text { innovation skills }\end{array}$ & $\begin{array}{c}\text { Communication } \\
\text { and collaborative } \\
\text { skills }\end{array}$ & & & \\
\hline 1 & 4.83 & 4.77 & 4.73 & 4.78 & 0.05 & Highest \\
\hline 2 & 4.88 & 4.90 & 4.93 & 4.90 & 0.03 & Highest \\
\hline 3 & 4.95 & 4.90 & 4.97 & 4.94 & 0.04 & Highest \\
\hline 4 & 4.85 & 4.93 & 4.93 & 4.90 & 0.05 & Highest \\
\hline 5 & 4.95 & 4.97 & 4.97 & 4.96 & 0.01 & Highest \\
\hline 6 & 4.90 & 4.90 & 5.00 & 4.93 & 0.06 & Highest \\
\hline 7 & 4.88 & 4.93 & 5.00 & 4.93 & 0.06 & Highest \\
\hline 8 & 4.85 & 4.87 & 4.93 & 4.88 & 0.04 & Highest \\
\hline 9 & 4.88 & 4.87 & 4.93 & 4.89 & 0.03 & Highest \\
\hline 10 & 4.90 & 4.90 & 4.93 & 4.91 & 0.02 & Highest \\
\hline & & Total & & 4.90 & 0.02 & Highest \\
\hline
\end{tabular}

Note. $0.01-1.50=$ Very low level, $1.51-2.50=$ Low level, $2.51-3.50=$ Medium level, $3.51-4.50=$ High level, $4.51-5.00=$ Highest level

\section{Conclusions, Discussions and Recommendation}

The perception towards the implementation of the Teacher Development Program based on Professional Learning Community, can promote teachers' learning and Innovation Skills, they can use the critical thinking and problem

solving skills, the creativity and innovation skills, and the communication and collaboration skills in highest level, and they can create innovation as activities to promote the students use the critical thinking and problem solving skills, the creativity and innovation skills, and the communication and collaboration skills, at the highest level too. Because the PLC approach focused on collaborative problem solving and the learning process emphasize develop students to achieve educational goals defined on the systematically, with the agreement of the members, the collaborative to learn and supportive among members (Hod, 2010). It is a collaboration to learn among professionals, under an atmosphere of trust, mutually share their knowledge to solve problems of student learning, through a discussion and suggestions including hearing ideas to AAR sincerity (Dufour, 2112). So that, the teacher development will be effective, must should be use the PLC approach to design the activities, because it provides the same profession that similar problems come together learning creation knowledge and skills and do not hinder in the routine.

\section{References}

Chou, C. H. (2011). Teachers' professional development: Investigating teachers' learning to do action research in a professional learning community. The Asia-Pacific Education Researcher, 20(3), 421-437. http://dx.doi.org/10.1016/j.sbspro.2010.03.404

Dufour, R., \& Dufour, B. (2012). The School Leader's Guide to Professional Learning Communities at Work. Retrieved from http://www.solutiontree.com

Graham, P. (2007). Improving Teacher Effectiveness through Structured Collaboration: A Case Study of a Professional Learning Community. RMLE Online: Research In Middle Level Education, 13(1), 1-17. http://dx.doi.org/10.1080/19404476.2007.11462044

Hord, S. M., Roussin, J. L., \& Sommers, W. A. (2010). Guiding Professional Learning Communities: Inspiration, Challenge, Surprise, and Meaning. California: Corwin. http://dx.doi.org/10.1080/13611267.2010.492955

Kemmis, S., \& Mc Taggert, R. (1988). The Action Research Planner. Australia: Deakin University Press. http://dx.doi.org/10.1007/978-981-4560-67-2 
Lieberman, A. (1995). Practices that support teacher development: Transforming conceptions of professional learning. Innovating and Evaluating Science Education: NSF Evaluation Forums, 1992-94, 67.

Office of the Educational Council. (2010a). A Research and Development of the Teacher and Education Personnel Development Policy. Bangkok: Prikwan Graphic.

Research Report: Research and Development of the Teacher and Education Personnel Development Policy, Bangkok: Prikwan Graphic. (2010b).

Panit, W. (2012). Way of learning for students in the $21^{\text {st }}$ century. Bangkok: Tathata Partnership for $21^{\text {st }}$ century skills. (2009). P21 Framework Definition. Retrieved from http://www.21 senturyskills.org

Rentfro, E. R. (2007). Professional learning communities impact student success. Leadership compass, 5(2), 1-3.

Snow-Gerono, J. L. (2005). Professional development in a culture of inquiry: PDS teachers identify the benefits of professional learning communities. Teaching and Teacher Education, 21(3), 241-256. http://dx.doi.org/10.1016/j.tate.2004.06.008

Vescio, V., Ross, D., \& Adams, A. (2008). A review of research on the impact of professional learning communities on teaching practice and student learning. Teaching and Teacher Education, 24(1), 80-91. http://dx.doi.org/10.1016/j.tate.2007.01.004

Williams, R. B., Brien, K., \& LeBlanc, J. (2012). Transforming Schools into Learning Organizations: Supports and Barriers to Educational Reform. Canadian Journal of Educational Administration and Policy, 13(134).

\section{Copyrights}

Copyright for this article is retained by the author(s), with first publication rights granted to the journal.

This is an open-access article distributed under the terms and conditions of the Creative Commons Attribution license (http://creativecommons.org/licenses/by/3.0/). 